Journal of Research in Nanoscience and Nanotechnology

Journal homepage:

http://akademiabaru.com/submit/index.php/jrnn/index ISSN: 2773-6180

\title{
Green synthesis of Sodium alginate mediated Fluorapatite Nanoparticle via Sol-Gel method
}

\author{
Pooneh Kia ${ }^{1 *}$, Mansor Bin Ahmad ${ }^{2}$, Kamyar Shameli ${ }^{3}$ \\ Institute of Bioscience, Universiti Putra Malaysia, 43400 UPM Serdang, Selangor, Malaysia ${ }^{1}$ \\ Department of Chemistry, Faculty of Science, Universiti Putra Malaysia, 43400 UPM Serdang, Selangor, \\ Malaysia ${ }^{2}$ \\ Malaysia-Japan International Institute of Technology (MJIIT), Universiti Teknologi Malaysia (UTM), Jalan \\ Sultan Yahya Petra, Kuala Lumpur 54100, Malaysia ${ }^{3}$ \\ * Correspondence: kia.pooneh@gmail.com; \\ https://doi.org/10.37934/jrnn.2.1.3041
}

\section{ABSTRACT}

Fluorapatite (FA) can be used as a bioactive substance in the body, especially the teeth implants. The FA nanoparticle was synthesized by adding the fluorine to the structure of HA using sol-gel method and the heat treatment of $700{ }^{\circ} \mathrm{C}$. Being low costs, eco-friendly and safer features are obvious advantages of the green synthesis of FA nanoparticles by using bio stabilizer of sodium alginate. Calcium nitrate tetrahydrate, diammonium phosphate, ammonium fluoride were used as precursors of $\mathrm{Ca}, \mathrm{P}$ and $\mathrm{F}$ respectively with the ratio of 1:67 Ca/P. The presence of crystal structure of HA and FA investigated by the results of XRD which confirmed the substitution of hydroxyl groups with the fluorine in the crystal structure of apatite. FTIR obtained that fluorine was substituted by hydroxyl groups in the structure of fluoridated hydroxyapatite by disappearing the hydroxyl groups at $3600 \mathrm{~cm}^{-1}$ in the FA. TGA investigated the thermal stability of the nanoparticles that showed the discrepancy of weight loss for HA and FA between $600^{\circ} \mathrm{C}$ to $800^{\circ} \mathrm{C}$. By using TEM, average sizes of 35 and $49 \mathrm{~nm}$ were determined for HA and FA respectively. FESEM results confirmed the shapes and distribution of particles of HA and FA in that, round like for the former and rode like for the later. The overall performance of utilizing sodium alginate (SA) as a bio-stabilizer is to obtain better precipitate which leads to having better crystallinity and smaller particle size and thermal stability remarkably improved.

Keywords:

Green synthesis, fluorapatite, hydroxyapatite, sol-gel, sodium alginate. 


\section{Introduction}

Nanotechnology has emerged up as a prominent science field which contains synthesis and formation of several nanomaterials [1]. Nanotechnology is greatly dependent on the size of nanoparticles, while the dimensions of particles have prominent effects on their specific features and properties Nanoparticles which can be specified with the size range of 1-100 nm are currently famous due to their great scientific interests and diverse purposes ranging from medical treatments to industry production [2].

Nanoparticles can be synthesized using a variety of methods including chemical, physical, biological or hybrid techniques these methods have been using high radiation and highly concentrated reductants and stabilizing agents that are harmful for the environmental and to human health [3]. Hence, biological synthesis of nanoparticles is a single step bio-reduction method and less energy is used with lower cost and water soluble to synthesize eco-friendly [4]. In general, green nano-biotechnology means synthesizing nanoparticles or the nanomaterials using biological routes such as those involving microorganisms, plants, and viruses or their byproducts, such as proteins and lipids, with the help of various biotechnological tools [5-8]. Among the nanoparticles, synthesis of hydroxyapatite (HA) and fluorapatite (FA) nanoparticles has gained the attention of scientists owing to their usable properties, green methods and relatively low cost [9-13]. Hydroxyapatite has known as $\mathrm{HA} ; \mathrm{Ca}_{10}\left(\mathrm{PO}_{4}\right)_{6}(\mathrm{OH})_{2}$ was well perused owing to its similarities with body hard tissues and its use as a bone replaced material cause of its bone bonding ability[14]. Fluorapatite with the formula of $\left(\mathrm{FA} ; \mathrm{Ca}_{10}\left(\mathrm{PO}_{4}\right)_{6} \mathrm{~F}_{2}\right)$ is also known as a bone repairing biomaterial, with antibacterial activities and significant biocompatibility features [15].

Synthetic of HA presents poor thermal stability, whilst it was indicated by the decomposition into other phases such as tricalcium phosphate (TCP; $\left.\mathrm{Ca}_{3}\left(\mathrm{PO}_{4}\right)_{2}\right)$ at sintering temperatures higher than $900^{\circ} \mathrm{C}$. This phase impurity often results in undesirable fast dissolution rates in vivo. In contrast, it is expected that fluorapatite $\left(\mathrm{Ca}_{5}\left(\mathrm{PO}_{4}\right)_{3} \mathrm{~F}\right)$ might have superior mechanical properties when sintered at high temperatures because of their higher thermal stability than HA [16]. Hence, there are some parameters that are helpful to improve and control the solubility of HA by substituting the hydroxyl group $\left(\mathrm{OH}^{-}\right)$with Fluor ions $\left(\mathrm{F}^{-}\right)$in the structure oh HA [17]. Various methods have been developed in an attempt to tailor the fluorine content of FA to achieve the best biological properties. FA can be either prepared using a solid-state reaction or a wet-chemical process [18], but the latter is used more commonly. Generally, it is possible to produce small particle size and high-purity FA powders using sol gel precipitation techniques, if the precipitation system and conditions are well controlled and there is a reproducible precipitate. There are several significant variables of the precipitation process such as solution concentration $(\mathrm{Ca} / \mathrm{P}$ ratio), $\mathrm{PH}$, acid addition rate, stirrer speed, temperature, reaction time and atmospheric condition [19].

Stabilizers are known as additives, which are substances added during the synthesis of nanoparticles to prevent agglomeration of the particles. They influence the size of the nano-materials being synthesized which results in different sizes and shapes gained and which range from nanoparticle clusters to complex nano-materials [20]. As an exemplary, Sodium alginate (SA) is a natural linear polysaccharide with the advantages of; biocompatible, non-immunogenic and not toxic. It is also a biodegradable polymer, which is the reason for its use in many biomedical applications [21]. Green synthesis method in the producing FA nanoparticle can be an alternative which should be conducted in the first main part of sol-gel method by adding natural biopolymer such as Sodium alginate as a bio-stabilizer for having better precipitate which lead to have better 
crystallinity due to obtaining the smaller particle size [22]. Sodium alginate can enhance cell attachment and osteoblast cells seeded on alginate scaffolds show better attachment and proliferation than on pure polymer scaffolds and enhance cell attachment and controlled size of particles [23].

In this study, sol-gel processing was used to synthesize the FA nanoparticles from HA powder. The advantages of the sol-gel method over other methods are precise control of composition, low processing temperature, and better homogeneity with high purity. There is no doubt that crystallinity shape and size significantly decrease by using bio stabilizer of SA.

\section{Materials and Methods}

\subsection{Materials}

Materials used for the synthesis of FA included the following: Calcium nitrate 4-hydrate (Ca $\left.\left(\mathrm{NO}_{3}\right)_{2} \cdot 4 \mathrm{H}_{2} \mathrm{O}\right)$ and diammonium hydrogen phosphate $\left(\left(\mathrm{NH}_{4}\right)_{2} \mathrm{HPO}_{4}\right)$ were supplied by Merck (GPR, USA); $\mathrm{NaOH}(99.0 \%)$ was obtained from (Merck, Germany); Ammonium fluoride $\left(\mathrm{NH}_{4} \mathrm{~F}\right)$ (Merck, USA), and Sodium alginate $\left(\mathrm{NaC}_{6} \mathrm{H}_{7} \mathrm{O}_{6}\right)$ obtained from (Sigma Aldrich USA) as a green stabilizer. All chemical reagents that were utilized in this research were of analytical grade and therefore needed no further purification before use. Distilled water was used to freshly prepare the solutions while all of the glassware which utilized in the various empirical process was subjected to cleaning with a fresh and pure solution of $\mathrm{HNO}_{3} / \mathrm{HCl}(3: 1, \mathrm{v} / \mathrm{v})$, and washed thoroughly with double distilled water, and dried before use.

\subsection{Formation of green synthesized fluorapatite nanoparticle via sol gel method}

The mixture of $100 \mathrm{ml}$ distilled water and $0.50 \mathrm{~g}$ sodium alginate was prepared first and was added into the $23.15 \mathrm{~g}$ of calcium nitrate 4-hydrate which was dissolved in $100 \mathrm{ml}$ distilled water followed by dropwise adding diammonium hydrogen phosphate $(79.08 \mathrm{~g})$ which was dissolved in $100 \mathrm{ml}$ distilled water. In order to have HA and FA respectively samples were divided into two containers owing to have fluorided HA. The quantity of the $x$ through $\mathrm{Ca}_{10}\left(\mathrm{PO}_{4}\right)_{6}(\mathrm{OH})_{2}-2 x F 2 x$ will be different by adding ammonium fluoride into FA container while $x=1$ and is $\left(11.21 \mathrm{~g} \mathrm{NH}_{4} \mathrm{~F}\right)$. The $\mathrm{PH}$ of the solutions must be kept between 10 and to 11 while stirring was done for all samples for $2 \mathrm{~h}$ and the precipitates were kept for $24 \mathrm{~h}$ in the room temperature. Then centrifuging and washing the samples by distilled water and samples were over-dried at $50{ }^{\circ} \mathrm{C}$. The dried precipitate was crushed by mortar and oven-dried before being put through a 50- micron sieve. Moreover, owing to calcination, $700{ }^{\circ} \mathrm{C}$ was used as a box furnace, while samples were crushed and sieved and prepared for characterizing (Scheme 1).

\subsection{Characterization of green synthesized fluorapatite nanoparticle via sol gel method}

Crystallinity of the synthesized FA and HA nano particles which were calcinated at $700{ }^{\circ} \mathrm{C}$ were determined with XRD -6000 (Shimaduz) X-ray diffraction instrument and the samples were run over a range of $5^{\circ}$ to $90^{\circ}$ theta. The transmission electron microscope (TEM) has utilized to specify the actual sizes and shapes of the synthesized nanoparticles. TEM observations made using an H-7100 electron microscope (Hitachi, Tokyo, Japan). Samples preparation was done by diluting with deionized water. The samples were then sonicated, dropped on a copper grid and oven-dried for 20 mins. Field emission scanning microscopy (FESEM) measurements were made in a (Jeol JSM-7600F) the instrument is mostly used for surface morphology determination of materials. Molecular analysis of the samples was conducted by (FT-IR Series 100, 1650 Perkin Elmer) spectrophotometer, whilst 
samples were obtained in the range of $200-4000 \mathrm{~cm}^{-1}$. The thermal analysis of the dried precipitate was carried out by TGA (Netzsch STA/409 C) in an ambient atmosphere at a heating rate of $10{ }^{\circ} \mathrm{C} /$ minute using $\alpha-\mathrm{Al}_{2} \mathrm{O}_{3}$ as reference material, while FA and $\mathrm{HA}$ powders were heated within the temperature range of $25^{\circ} \mathrm{C}$ to $1000{ }^{\circ} \mathrm{C}$.

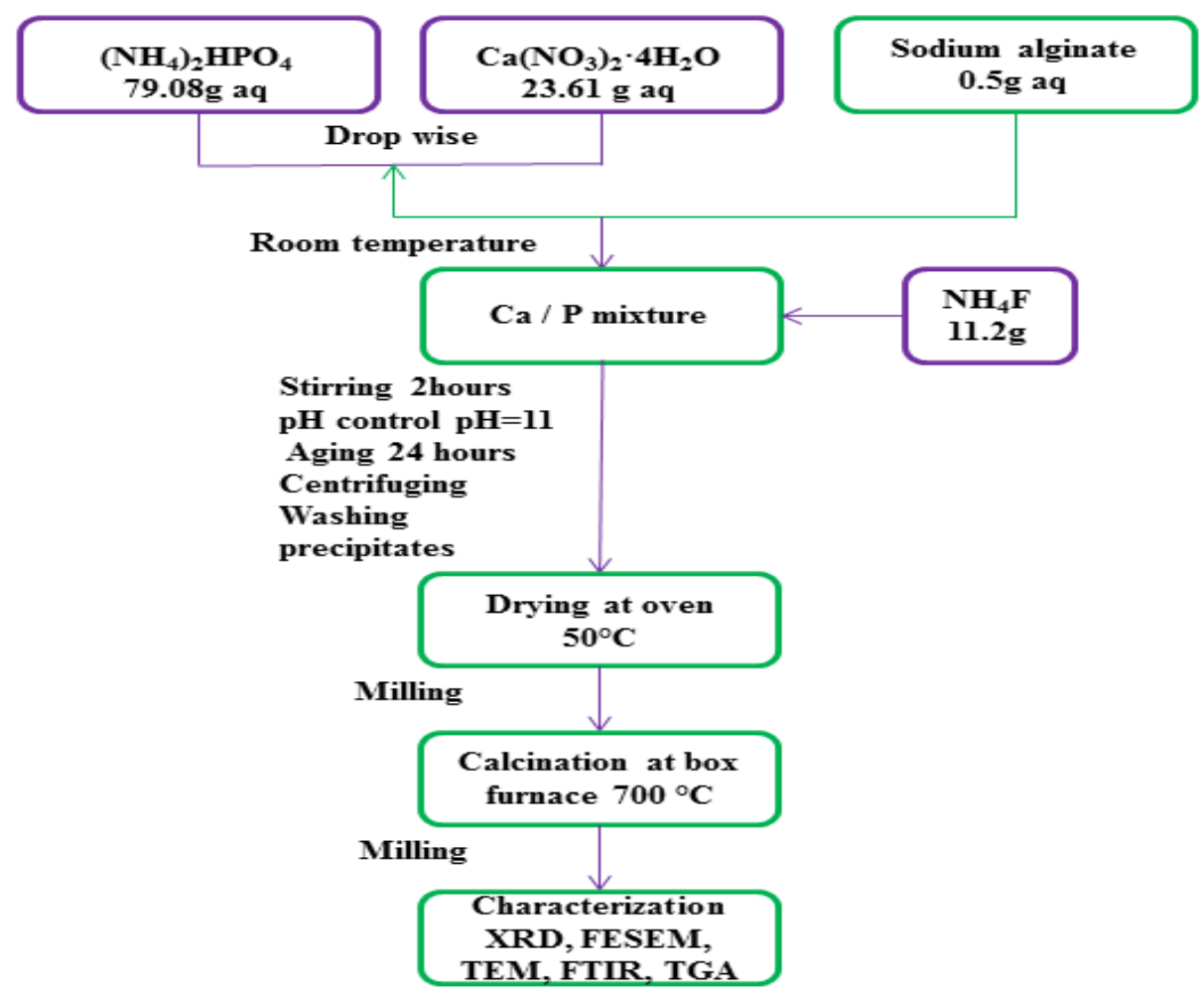

Scheme 1. Preparation of HA and FA with SA by sol-gel method

\section{Results and Discussion}

The synthesis of nanocrystals with controllable sizes is very important to characterize the sizedependent physical properties of nanocrystals. Stabilizers are known as additives, which are substances added during the synthesis of nanoparticles to prevent agglomeration of the particles. SA as a capping agent prevented uncontrolled growth and agglomeration of nanoparticle. Figure 1, indicates the difference stages of FA that divided to water phase and precipitate phase, which is obvious illustration of the effect of SA as a bio-stabilizer in the solution that indicated the better dispersion of FA. 


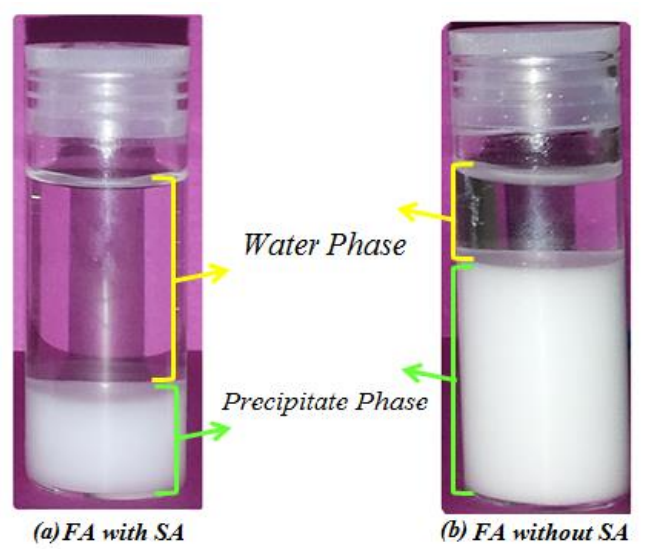

Figure 1.The discrepancy of the presence of SA in the solution of FA.

\subsection{Identify the crystalline structure of FA nanoparticle by using X-ray diffraction (XRD)}

XRD crystallinity patterns of HA and FA nanoparticles by using the bio-stabilizer of SA was shown in (Fig 2). The size, crystalline structure of HA powders were primarily investigated by XRD in Figure 3 that reveals the presence of crystalline nano meter sized of HA between range of $\left(23^{\circ}-47^{\circ}\right)$ at $2 \theta$ which are $(202,210,211,310,222)$ respectively [24]. The XRD indicated the most intense peaks for FA at $2 \theta,(102,211,112,300,202,310,222$, and 004$)$ which were located between $\left(28^{\circ}-35^{\circ}\right)$, while the most intense ones for HA declined or vanished. Whilst the peak shifts, are reflected the change in lattice parameters of the apatite structures that resulting from the fluorine incorporation. To some extent, two new peaks at 28.42 and $55.92 \theta$ were emerged and as it can be seen intensity of the peak for 47.18 significantly increased in FA. It should be also noted that the 35.5 peak become much sharper and the peak gradually split into two peaks as the fluorine concentration, which describe the crystallinity changes with increased fluorine substitution [25]. All results jointly indicated that presence of SA in the solution significantly decreases the crystallinity size of the obtained products. Hence, it can be determined that the incorporation of fluorine into the structure of HA matrix could promote the crystallinity of the host crystals. By decreasing the crystallinity, chemical and thermal stability of the FA could increase inevitably. 


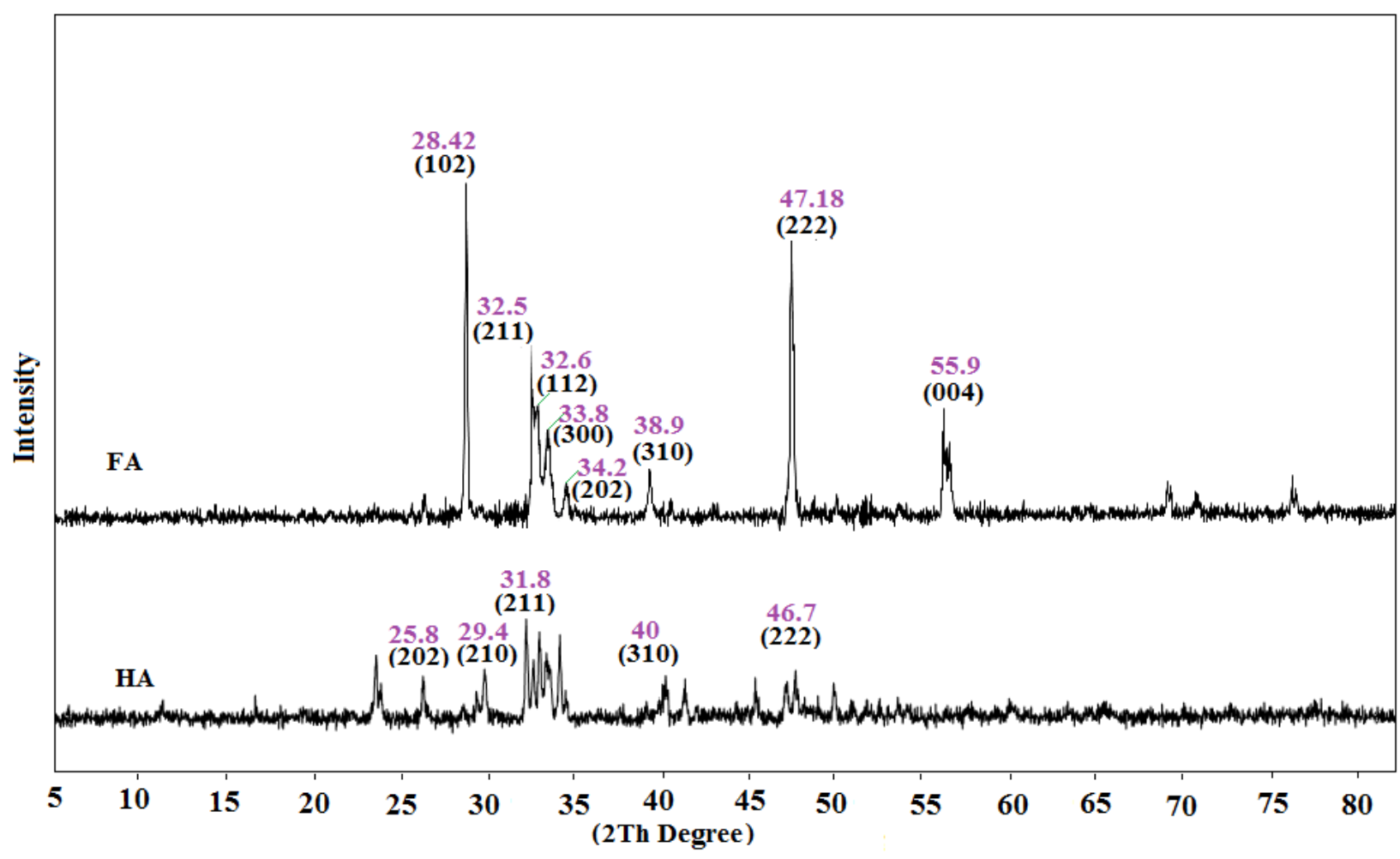

Figure 2. XRD pattern of FA and HA with SA by using Sol-gel method at $700{ }^{\circ} \mathrm{C}$.

3.2. Identification of characteristic functional groups in nanoparticle samples by fourier-transform infrared spectroscopy

FTIR analysis was done for the samples HA and FA prepared by using bio stabilizer of SA at 700 ${ }^{\circ} \mathrm{C}$ (Fig 3). By substituting the $\mathrm{F}^{-}$ions to the structure of HA, peaks are willing to become wider with more stretching features. The peak at $631 \mathrm{~cm}^{-1}$ belongs to fluoride that obviously emerged in FA. The bond at $1034 \mathrm{~cm}^{-1}$ occurred from $\mathrm{PO}_{4}^{3-}$ bond. The bond at $570 \mathrm{~cm}^{-1}$ also occurred from $\mathrm{PO}_{4}{ }^{3-}$ bond. The starching band which was seen at $3600 \mathrm{~cm}^{-1}$ is because of the stretching mode of $\mathrm{OH}^{-}$group in $\mathrm{HA}$ structure. Whilst it may be explained that the peak at $3600 \mathrm{~cm}^{-1}$ is seems to be faded by increasing the of $\mathrm{F}^{-}$ions [26]. Most of the $\mathrm{OH}^{-}$groups were well substituted with $\mathrm{F}^{-}$ions in the structure of $\mathrm{HA}$ phase. It must also mentioned that, some carbonate content was seen as $\left(\mathrm{CO}_{3}{ }^{-2}\right)$ peak about $870 \mathrm{~cm}^{-1}$ and $1400 \mathrm{~cm}^{-1}$, whilst that of $870 \mathrm{~cm}^{-1}$ was not tangible in FA that may be originated from the absorption of carbon dioxide from the atmosphere, which can be a prominent illustration of the presence of carbonate along with fluoride in the structure of apatite [27]. Consequently, according to these statements; it is clear that the synthesized nano powders are indeed fluorapatite [28]. 


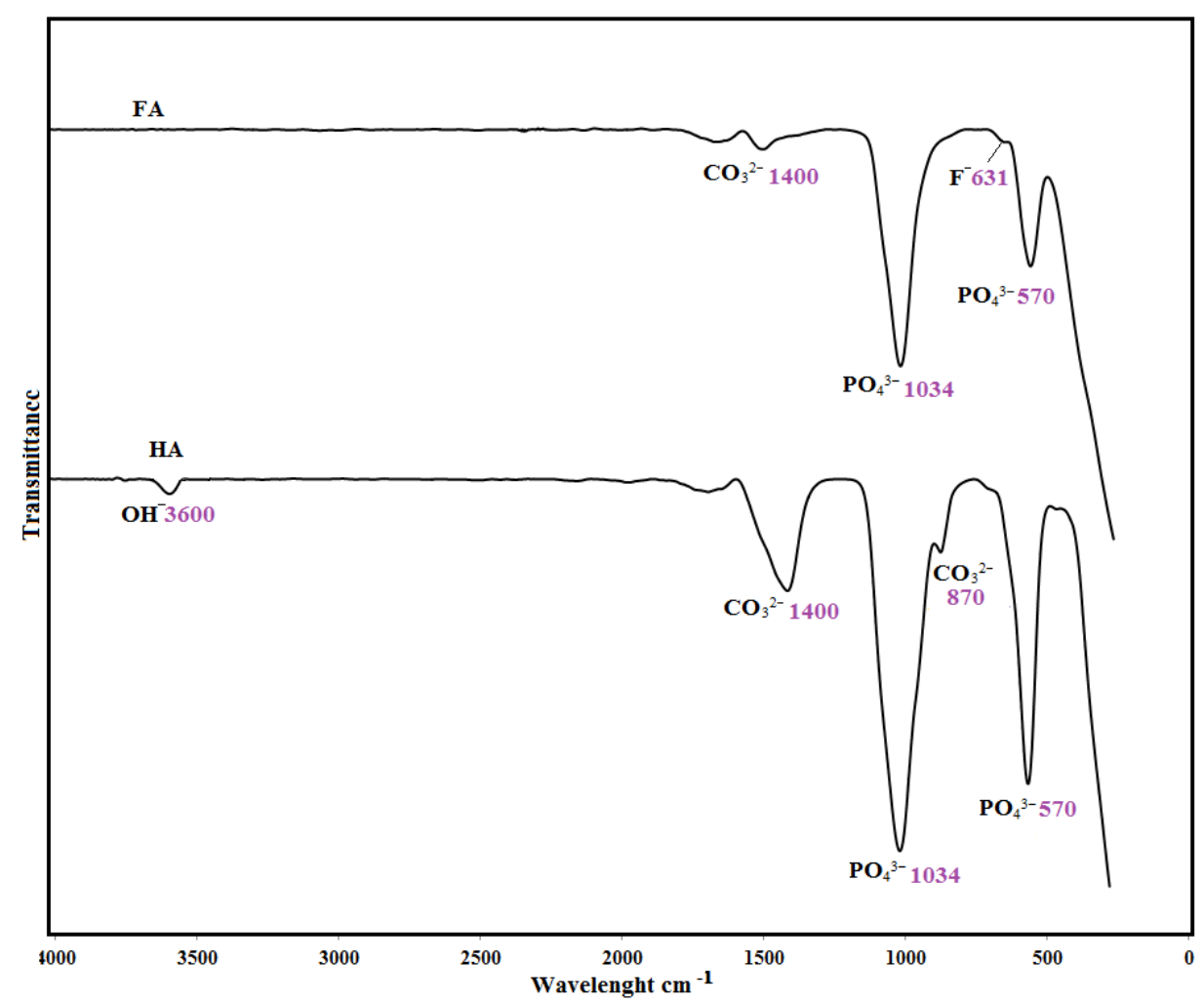

Figure 3. FTIR results of FA and HA with SA by using sol-gel method at $700{ }^{\circ} \mathrm{C}$.

\subsection{Identification of thermal stability of the synthesized nanoparticles by TGA}

Thermogravimetric analysis data of FA and HA were indicates that HA nano-powder witnessed three levels of losing weight. The first stage which was belong to the evaporation of absorbed water in the nano-powders, was about $200{ }^{\circ} \mathrm{C}$, the second level was from $600{ }^{\circ} \mathrm{C}$ to $800{ }^{\circ} \mathrm{C}$ belongs to the release of hydroxyl groups of the HA crystals, and the final third level which is not tangible above $1000{ }^{\circ} \mathrm{C}$ was belong to the major decomposition of the HA [29]. Consequently the huge weight loss that belongs to whole $\mathrm{OH}^{-}$groups, in contrast by fluoride substitution thermal stability of the HA structure was considerably increased and the decomposition of the HA structure effectively was controlled and restrained. HA thermal stability would significantly increase or the decomposition of the HA structure could be effectively retarded. Weight loss in FA nanoparticles is related to the first loss stage of $\mathrm{OH}^{-}$groups, same weight loss can be seen between $600{ }^{\circ} \mathrm{C}$ to $800{ }^{\circ} \mathrm{C}$ which is higher than in that of $200{ }^{\circ} \mathrm{C}$ that related to huge loss of water and whole $\mathrm{OH}^{-}$groups [30] (Fig 4). 

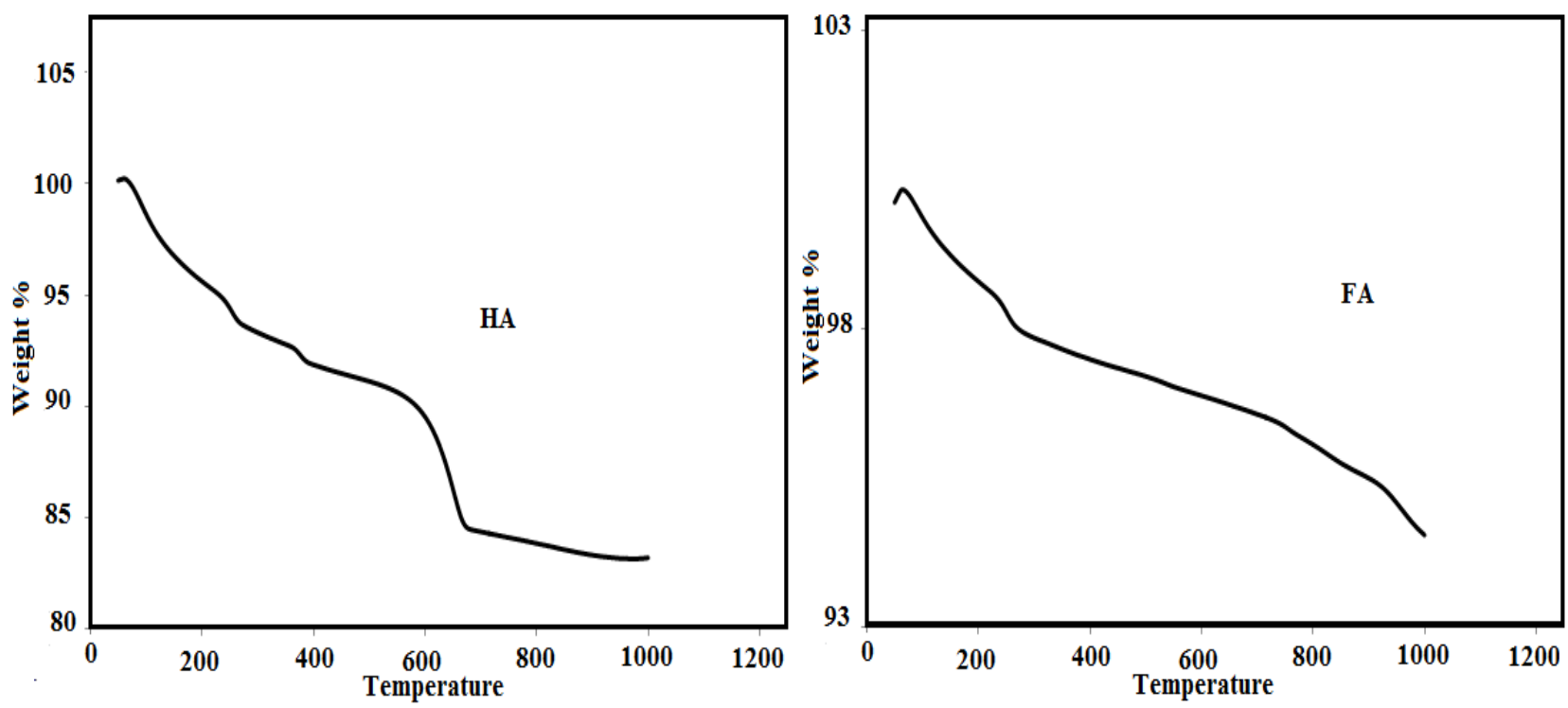

Figure 4. TGA results of FA and HA with SA by using sol-gel method at $700{ }^{\circ} \mathrm{C}$.

\subsection{Morphological Analysis of Nanoparticles by FESEM}

The SEM micrographs and related EDX data analysis of the synthesized samples of HA and FA by using SA are shown in the Fig 5 and 6, respectively. Microstructure of the HA crystallite was seen as roughly like a round with crystallite size of less than $50 \mathrm{~nm}$, while micrographs of FA indicated that particles had perfectly rod-like shape (Fig 6). FA particle diameters were about $49 \mathrm{~nm}$ in length and $10 \mathrm{~nm}$ in wide with less agglomeration and small size due to presence of SA as a bio-stabilizer. By fluoride ion substitution the morphology of particles from HA to FA slightly changed and there is no doubt that presence of SA promotes the particle size become smaller with better crystallinity [31, 32]. As in can be seen in EDX results of HA and FA all essential elements were indicated specially fluoride ion emerged at $0.67 \mathrm{eV}$ in $\mathrm{FA}$.
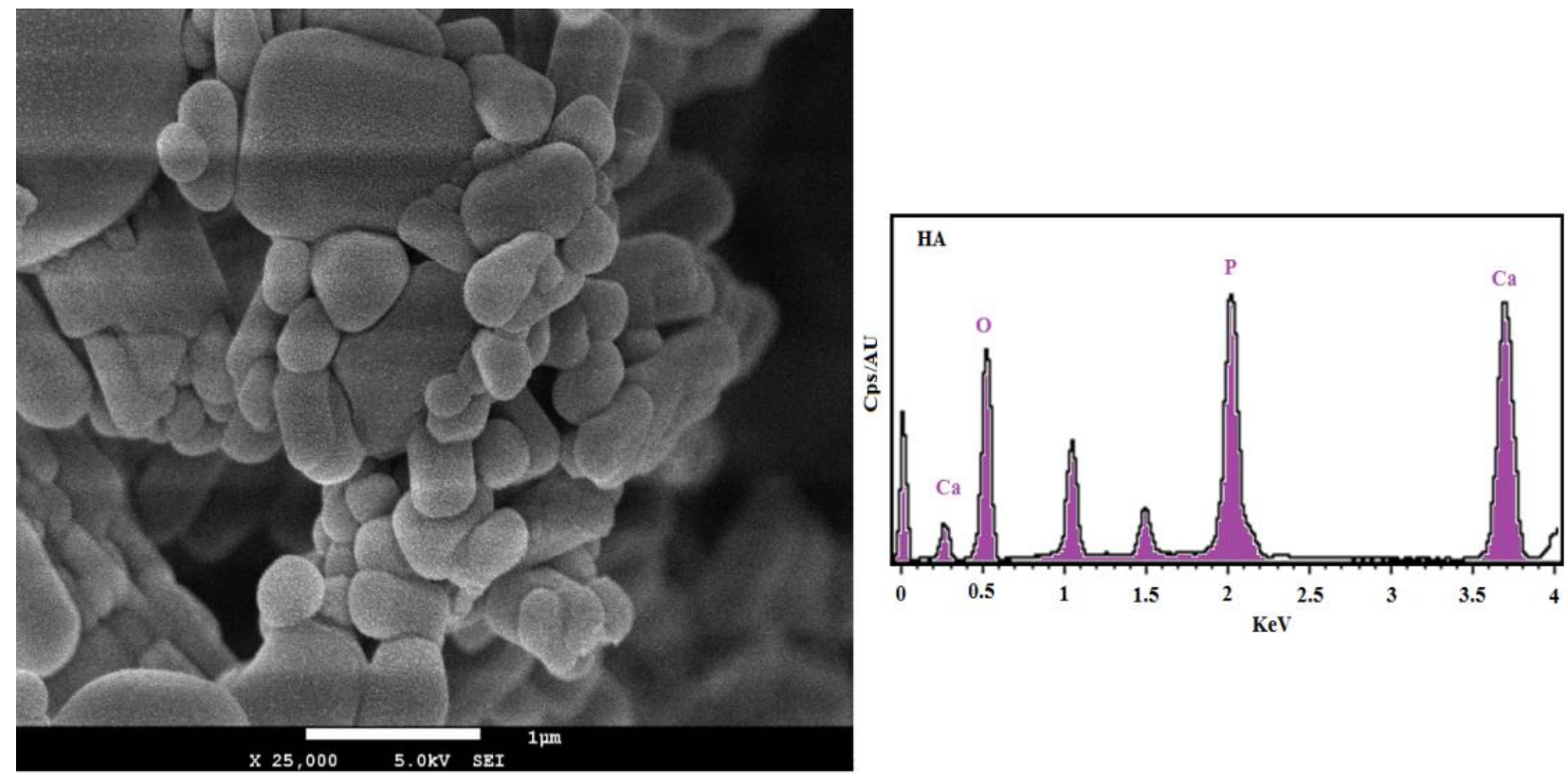

Figure 5. FESEM and EDX results of HA with SA by using sol-gel method at $700{ }^{\circ} \mathrm{C}$. 

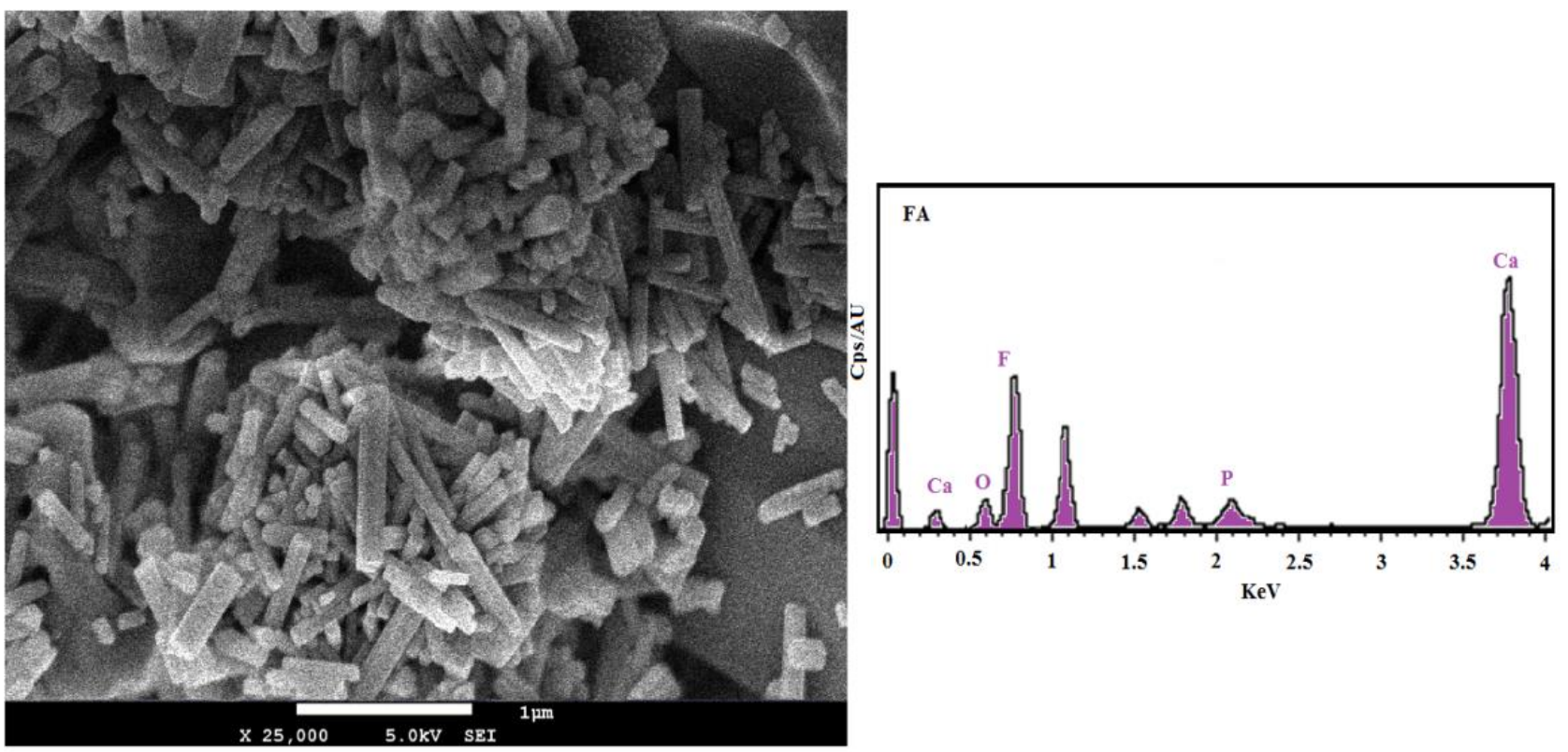

Figure 6. FESEM and EDX results of FA with SA by using sol-gel method at $700{ }^{\circ} \mathrm{C}$.

\subsection{Morphology and particle size distribution of the FA and HA}

Nano powders morphology shapes and sizes were observed by TEM that indicate the nanocrystal line nature of materials. TEM images of the HA crystallite were almost round-like with a mean crystallite size of $34.71 \mathrm{~nm}$ (Fig 7). TEM image reveal that FA powders are composed of nano crystalline particles with the average particle size of less than $50 \mathrm{~nm}$ (Fig 8). The average diameter and length of FA crystals were found to be rod-like, and their lengths and width diameters were 49.34 and $10.92 \mathrm{~nm}$ respectively [33]. Hence the particles become highly crystallized. Taking into consideration the impact of fluoride concentration on the morphology of the precipitated apatites, it was discovered that the increase in fluoride ion concentration would result in a decrease of the aspect ratio of the produced crystallites. Based on the TEM images, the aspect ratio of FA particle is considerably reduced in respect of the HA particles [34].
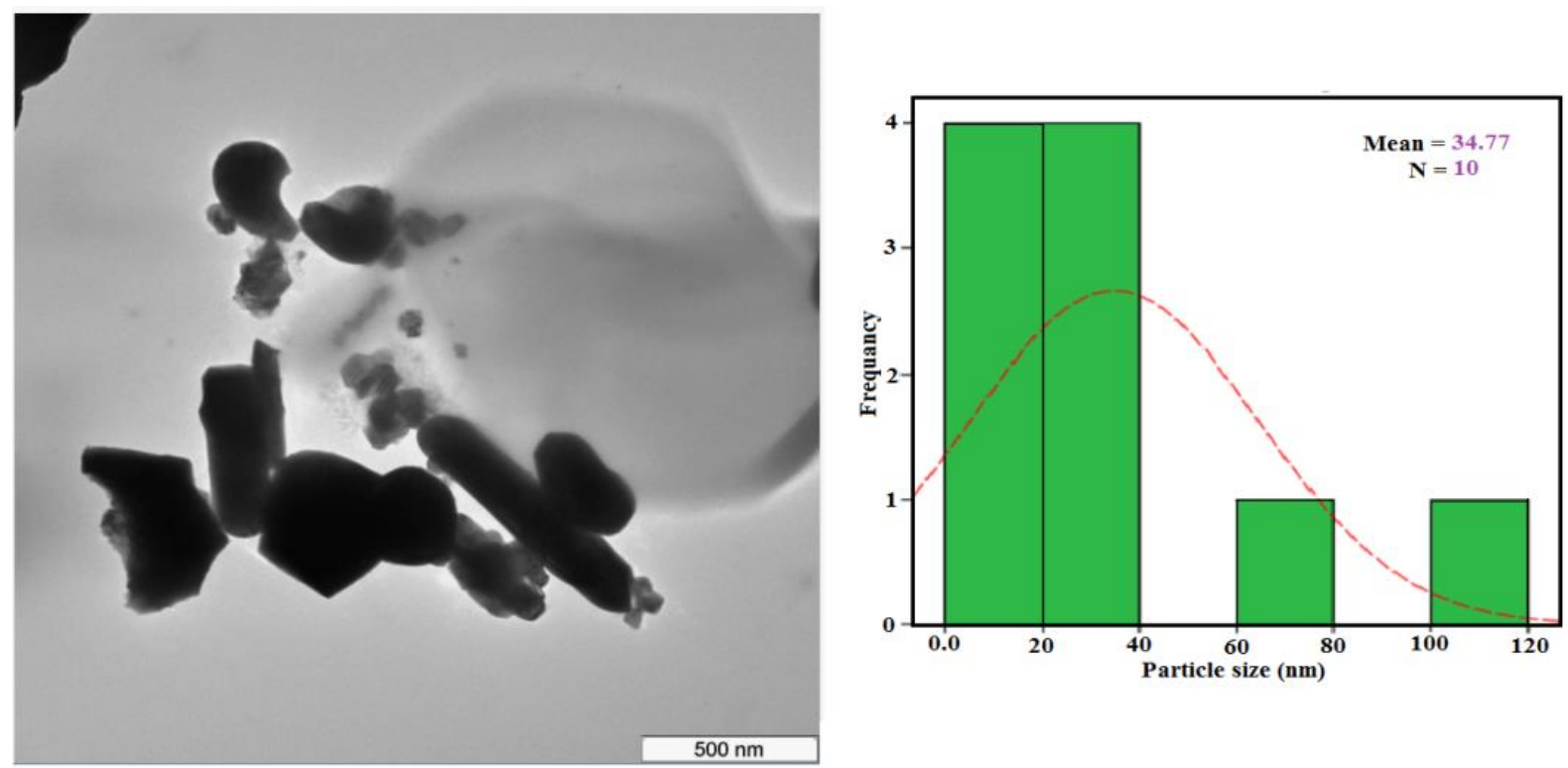

Figure 7. TEM and histogram results of HA with SA by using sol-gel method at $700{ }^{\circ} \mathrm{C}$. 

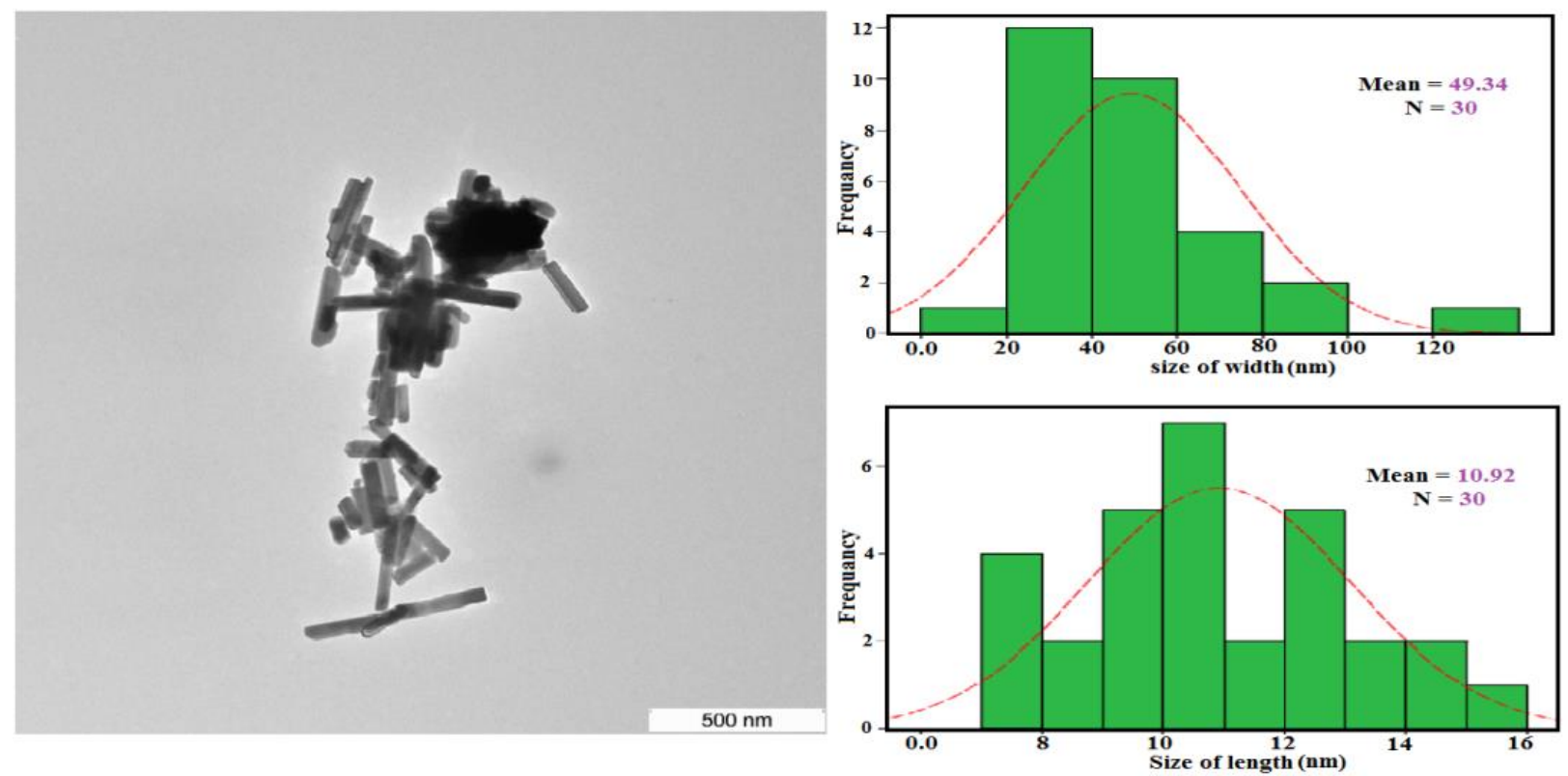

Figure 8. TEM and histogram results of FA with SA by using sol-gel method at $700{ }^{\circ} \mathrm{C}$.

\section{Conclusions}

The sol-gel method was used for preparing HA and FA production which was utilized as a green synthesize for producing fluoride substitute apatites. Bio-stabilizer of SA effected on the crystallinities, were added to the batch from beginning of the reactions. Ammonium fluoride was selected as the donor for fluoridation of the apatite. This phenomenon could be described that when the fluoride well replaced by hydroxyl groups in the HA structure, a better level of chemical and thermal stability of the FA nanoparticle was achieved. XRD data of the FA nanoparticles at $700{ }^{\circ} \mathrm{C}$ indicated the crystallinity of FA with the sharp peaks in range of $23^{\circ}-47^{\circ}$ at $2 \theta$. TEM technique showed that with the addition of fluoride crystallites significantly was decreased for FA about 34 to $10 \mathrm{~nm}$ in length and wide. FESEM results indicate the well rod like morphology of FA crystals. The better and finer size will be achieved by the presence of SA in the structure of FA, while all primary elements were detected by EDX results. TGA data of the FA nano-powders in the various thermal range from $25{ }^{\circ} \mathrm{C}$ to $1000{ }^{\circ} \mathrm{C}$, revealed that when the fluorine content was completely substituted in the HA structure, the thermal stability of the HA matrix was increased and the decomposition of the HA structure was effectively restrained cause of substitution of flour ions with hydroxyl group which correspond to the loss of physically adsorbed water. These results are the well confirmed by FTIR peaks when the hydroxyl group disappears in FA result.

\section{Acknowledgment}

The author would like to express sincere gratitude to the university Putra Malaysia for the characterizations supports and the staffs and the UPM institute of bio since (IBS).

\section{References}

1. K. Shameli, M. Ahmad, S. D. Jazayeri, P. Shabanzadeh, H. Jahangirian, M. Mahdavi, and Y. Abdollahi. Synthesis and characterization of polyethylene glycol mediated silver nanoparticles by the green method. Int. J. Mol. Sci., 2012, 13(6 ), pp. 6639-6650. doi: 10.3390/ijms13066639. 
2. M. Ahmad, Y. T. Mei, K. Shameli, M. Z. Hussein, and J. J. Lim. Green synthesis and characterization of silver/chitosan/polyethylene glycol nanocomposites without any reducing agent. Int. J. Mol. Sci., 2011, 12(8), pp. 4872-84. doi: 10.3390/ijms12084872.

3. K. Shameli, M. Ahmad, W. Z. W. Yunus, and N. A. Ibrahim. Synthesis and characterization of silver/talc nanocomposites using the wet chemical reduction method. Int. J. Nanomedicine., 2010, 5, 743. doi: 10.2147/IJN.S13227.

4. F. Namvar, S. Azizi, M. Ahmad, K. Shameli, R. Mohamad, M. Mahdavi and P. M. Tahir. Green synthesis and characterization of gold nanoparticles using the marine Macroalgae Sargassum Muticum. Res. Chem. Intermed., 2015, 41(8), pp. 5723-30. doi: 10.1007/s11164-014-1696-4.

5. H. Jahangirian, M. H. S. Ismail, M. J. Haron, R. Rafiee-Moghaddam, K. Shameli and S. Hosseini. Synthesis and characterization of zeolite/ $\mathrm{Fe}_{3} \mathrm{O}_{4}$ nanocomposite by green quick precipitation method. Dig. J. Nanomater. Biostruct., 2013, 8.(4), pp. 1405-1413.

6. R. Khandanlou, M. Ahmad, H. R. Fard Masoumi, K. Shameli and M. Basri, Rapid adsorption of copper (II) and lead (II) by rice straw/Fe3 $\mathrm{O}_{4}$ nanocomposite: optimization, equilibrium isotherms, and adsorption kinetics study. PloS one., 2015, 10.(3), pp. 1-19. doi: 10.1371/journal.pone.0120264.

7. Z. Izadiyan, K. Shameli, M. Miyake, H. Hara, S. H. Mohd Taib and E. Rasouli, Cytotoxicity assay of plantmediated synthesized iron oxide nanoparticles using Juglans regia green husk extract. Arab. J. Chem., 2020, 13.(1), pp. 2011-2023. doi; 10.1016/j.arabjc.2018.02.019.

8. R. Khandanlou, M. Ahmad, K. Shameli and K. Kalantari, Synthesis and characterization of rice straw/ $/ \mathrm{Fe}_{3} \mathrm{O}_{4}$ nanocomposites by a quick precipitation method. Molecules, 2013, 18.(6), 6597-6607. doi: 10.3390/molecules18066597.

9. K. X. Lee, K. Shameli, Y. P. Yew, S. Y. Teow, H. Jahangirian, R. Rafiee-Moghaddam and T. J. Webster. Recent developments in the facile bio-synthesis of gold nanoparticles (AuNPs) and their biomedical applications. Int. J. Nanomed., 2020, 15, pp. 275-300. doi: 10.2147/IJN.S233789.

10. P. Shabanzadeh, N. Senu, K. Shameli, F. Ismail, A. Zamanian, and M. Mohagheghtabar. Prediction of silver nanoparticles' diameter in montmorillonite/chitosan bionanocomposites by using artificial neural networks. Res. Chem. Intermed., 2015, 41(5), pp. 3275-3287. doi: 10.1007/s11164-013-1431-6.

11. P. Shabanzadeh, R. Yusof, and K. Shameli. Modeling of biosynthesized silver nanoparticles in Vitex negundo L. extract by artificial neural network. RSC Advances., 2015, 5(106), pp. 87277-87285. doi: 10.1039/C5RA11940E.

12. P. Shabanzadeh, N. Senu, K. Shameli and M. Mohaghegh Tabar. Artificial intelligence in numerical modeling of silver nanoparticles prepared in montmorillonite interlayer space. J. Chem., 2013, 2013, pp. 1-8. doi: 10.1155/2013/305713.

13. S. K. Balavandy, K. Shameli, and Z. Z. Abidin, Rapid and green synthesis of silver nanoparticles via sodium alginate media. Int. J. Electrochem. Sci., 2015., 2015, 10.(1), 486-497.

14. P. Khadeeja, V. Banse and L. Ledwani. Green synthesis of nanoparticles: their advantages and disadvantages. Paper presented at the AIP conference proceedings., 2016. doi:10.1063/1.4945168.

15. K. Omer, G. Vural, S. Keser, I. S. Yahia, N. Bulut, T. Ates and S. Koytepe. Ce/Sm co-doped hydroxyapatites: synthesis, characterization, and band structure calculation. J. Aust. Ceram. Soc., 2021, 57(1), pp. 305-17. doi: 10.1007/s41779-020-00533-6.

16. R. Alireza, A. Kamyar, M. Khakbiz and H. Basiri. Synthesis and characterization of strontium fluorhydroxyapatite nanoparticles for dental applications. Microchem. J., 2020, 153(104485), pp. 1-7. doi: 10.1016/j.microc.2019.104485.

17. C. Yanming, and X. Miao. Thermal and chemical stability of fluorohydroxyapatite ceramics with different fluorine contents. Biomaterials., 2005, 26(11), pp. 1205-1210. doi: 10.1016/j.biomaterials.2004.04.027.

18. M. Tahriri, M. Soulati-Hashjin and E. Hossein. Synthesis and characterization of hydroxyapatite nanocrystals via chemical precipitation technique. Iranian Journal of Pharmaceutical Sciences., 2008, 4(2), pp. 127-134. 
19. C. P. Dhanalakshmi, L. Vijayalakshmi, and V. Narayanan. Synthesis and characterization of fhap/chitosan nanocomposite and its biomedical application. Int. J. Nano \& Matl. Sci., 2012, 1(2), pp. 81-96.

20. I. Nikčević, V. Jokanović, M. Mitrić, Z. Nedić, D. Makovec, and D. Uskoković. Mechanochemical synthesis of nanostructured fluorapatite/fluorhydroxyapatite and carbonated fluorapatite/fluorhydroxyapatite. Journal of Solid State Chemistry., 2004, 177(7), pp. 2565-2574. doi: 10.1016/j.jssc.2004.03.024.

21. C. Rey. Calcium Phosphates for Medical Applications. Calcium Phosphates in Biological and Industrial Systems, 1998, pp. 217-251. doi: 10.1007/978-1-4615-5517-9-10.

22. J. Ramyadevi, K. Jeyasubramanian, A. Marikani, G. Rajakumar, A. A. Rahuman. Synthesis and antimicrobial activity of copper nanomaterials. Mater. Lett., 2012, 71, pp. 114-116. doi: 10.1016/j.matlet.2011.12.055.

23. V. N. Kuznetsov, L. B. Sukhodub, and L. F. Sukhodub. The study of the alginate/hydroxyapatite composites structural properties. Proceedings of the International Conference Nanomaterials: Applications and Properties., 2014, 3(2), 02NABM03, pp. 1-3.

24. Y. Luo, A. Lode, C. Wu, J. Chang, and M. Gelinsky. Alginate/nanohydroxyapatite scaffolds with designed core/shell structures fabricated by $3 \mathrm{~d}$ plotting and in situ mineralization for bone tissue engineering. ACS Appl. Mater. Interfaces., 2015, 7(12), pp. 6541-6549. doi: 10.1021/am508469h

25. A. Dubnika, D. Loca, and L. Berzina-Cimdina. Functionalized hydroxyapatite scaffolds coated with sodium alginate and chitosan for controlled drug delivery. Poly. Sci., 2016, 61,(3). pp. 193-199. doi: 10.3176/proc.2012.3.08

26. P. Nasker, A. Samanta, S. Rudra, A. Sinha, A. K Mukhopadhyay and M. Das. Effect of fluorine substitution on sintering behaviour, mechanical and bioactivity of hydroxyapatite. J. Mech. Behav. Biomed. Mater., 95 2019, 95, 136-42. doi: 10.1016/j.jmbbm.2019.03.032.

27. M. R. M. Roslan, N. L. M. Kamal, M. F. A. Khalid, N. F. M. Nasir, E. M. Cheng, C. Y. Beh, J. S. Tan and M. S. Mohamed. The state of starch/hydroxyapatite composite scaffold in bone tissue engineering with consideration for dielectric measurement as an alternative characterization technique. Materials., 2021, 14(8). 1960, pp. 1-17. doi: 10.3390/ma14081960.

28. H. Gul, M. Khan and A. S. Khan. Bioceramics: Types and clinical applications. In Handbook of Ionic Substituted Hydroxyapatites. Elsevier Publisher., 2020, pp. 53-83. doi: 10.1016/B978-0-08-102834-6.00003-3.

29. C. Rao, R. Wang, Y. Yang, F. Hatert, Q. Xia, X. Yue, W. Wang. Insights into post-magmatic metasomatism and li circulation in granitic systems from phosphate minerals of the nanping no. 31 pegmatite (SE China). Ore Geol. Rev., 2017, 91, pp. 864-76. doi: 10.1016/j.oregeorev.2017.08.017.

30. D. Kherifi, H. Belhouchet, S. Ramesh, K. Y. Sara Lee, A. Kenzour, S. Djoualah, M. K. G. Abbas, Y. H. Wong, S. Ramesh. Sintering behaviour of fluorapatite-silicate composites produced from natural fluorapatite and quartz. Ceram. Int., 2021, 47, pp. 16483-16490. doi: 10.1016/j.ceramint.2021.02.216.

31. D. Thi Le, T. P. T. Le, H. T. Do, H. T. Vo, N. T. Pham, T. T. Nguyen, H. T. Cao, P. T. Nguyen, T. M. T. Dinh, H. V. Le and D. L. Tran. Fabrication of porous hydroxyapatite granules as an effective adsorbent for the removal of aqueous $\mathrm{Pb}$ (II) ions. J. Chem., 2019, 2019(8620181), pp. 1-10. doi: 10.1155/2019/8620181.

32. R. E. K. Billah, Y. Abdellaoui, Z. Anfar, G. Giácoman-Vallejos, M. Agunaou, A. Soufiane. Synthesis and characterization of chitosan/fluorapatite composites for the removal of $\mathrm{Cr}(\mathrm{VI})$ from aqueous solutions and optimized parameters. Water Air Soil Pollut., 2020, 231(163), pp. 1-14. doi: 10.1007/s11270-020-04535-9.

33. A. Altaie, N. Bubb, P. Franklin, M. J. German, A, Marie, D. J. Wood. Development and characterisation of dental composites containing anisotropic fluorapatite bundles and rods. Dent. Mater., 2020, 8, pp. 1071-1085. doi: 10.1016/j.dental.2020.05.003.

34. M. Okazaki, Comparison of hexagonal crystal structures between fluorapatite and polytetrafluoroethylene. Biomed. Mater. Eng., 2017, 28(1), pp. 3-8. doi: 10.3233/BME-171650. 